\title{
Kissing Pedro Martinez: (Existential) Anankastic Conditionals and Rationale Clauses
}

\author{
Jon Nissenbaum \\ McGill University
}

\section{Introduction: Necessay Conditions}

The main clauses in (1) and (2) are understood as stating necessary conditions for achieving the goals expressed in the if-clauses (1) and in the rationale-clauses (2).

\section{(1) Anankastic conditionals}
a. If you want to go to Harlem, you must take the A train. [Sab $\phi$ 2001]
b. If you want to become mayor, you have to go to the pub regularly.
c. If you want to be healthy, you should drink more tea.
[Kratzer 1981]
d. If you want to dance professionally, you need to practice every day.

(2) Corresponding rationale clauses
a. You must take the A train in order to go to Harlem. [Strayhorn/Sab $\phi$ ]
b. You have to go to the pub regularly in order to become mayor.
c. You have to drink tea to be healthy.
d. You need to practice every day to dance professionally.

Sentences like (1), which have been called Anankastic (from the Greek word for necessity), have the outward form of conditionals. But their meanings differ from those of ordinary indicative conditionals in interesting respects-apart from the curious fact that the if-clause can be replaced by an infinitival rationale-clause. It is odd, for example, for a conditional sentence like (1a) to imply (3). Why would a sentence of the form (4a) mean the same thing as one of the form (4b)?

(3) If you do not take the A train, you will not go to Harlem.
a. [if ... want to $p$, then must $q]=$
b. [if not $q$, then not $p$ ]

Ordinary indicative conditionals do not have this property. Compare the Anankastic conditional (5a) with the superficially similar (5b). This pair from Sæbø (2001) is modeled after an observation by Hare (1963). While (5a) is equivalent to (6a), (5b) does not mean the same thing as (6b).

(5) a. If you want to be owner of America, you need to find the golden helmet.

b. If you want to be owner of America, you need to see a psychiatrist.

(6) a. If you do not find the helmet, you cannot be the owner of America.

b. \#If you do not see a psychiatrist, you cannot be the owner of America. 
Several recent papers have addressed the problem of Anankastic conditionals, seeking to show how their meanings can be explained by the same theory that has been successful in characterizing the meanings of other conditionals (that of Kratzer 1981, 1991). In this paper, I will discuss a set of facts that challenge these recent attempts. Alongside of the 'necessity conditionals' that have been the focus of attention, sits another class that might be called 'sufficiency conditionals' with possibility modals in place of the necessity modals:
Sufficiency conditionals?
a. If you want to go to Harlem, you can take the A train.
b. If you want to become mayor, you could go to the pub regularly.
c. If you want to be healthy, you could drink more tea.
d. If you want a decent grade, you can write a really good paper.

Like Anankastics, the sentences in (7) can be paraphrased with rationale clauses:
a. You can take the A Train in order to go to Harlem.
b. You could go to the pub regularly in order to become mayor.
c. You could drink tea to be healthy.
d. You can write a really good paper to get a decent grade.

In all of these sentences, the "consequent" provides a sufficient condition for achieving the desire expressed in the if-clause/rationale clause. Both (7a) and (8a) assert that 'taking the A train is one of the ways you could get to Harlem'. And they both imply (9), suggesting an odd equivalence (10) parallel to (4), the equivalence that holds for Anankastics with universal modals. ${ }^{1}$

If you take the A Train, you (will) get to Harlem.
a. [if ... want to $p$, then can $q$ ]
$=$
b. [if $q$, then $p]$

Thus, these sentences seem to be in relevant respects the 'existential' versions of Anankastics. We might as well designate them 'Eparkastic Conditionals' (from the Greek for 'sufficiency').

My goals in this paper are to summarize current approaches to the semantics of anankastics (section 3), then to show why examples like (7)-(8) challenge those approaches (section 4). To foreshadow, I will try to show that the current theories, while making correct predictions about the meanings of (7)-(8), also predict wrongly that (11) could be true in a world much like the real one.

(11) \#If you want to go to Harlem, you can kiss Pedro Martinez. 
I will then suggest a way to address the problem (section 5). The idea is based on the observation that rationale clauses appear in non-modal environments (12a), where they are understood as expressing something about the goal that is related to an agent's action. Thus (12b) is nonsensical, if Varitek is rational.

(12) a. Varitek took the A Train to go to Harlem.

b. \#Varitek kissed Pedro Martinez to go to Harlem.

Appropriating an idea of von Fintel \& Iatridou (2004), I'll suggest that anankastic (and eparkastic) sentences embed (sometimes elliptical) purposive rationale clauses, but in the scope of the modal operator (as in 13). I will argue that if this is correct, the deviance of (11) follows from the deviance of (12b).
a. If you want to go to Harlem, you can kiss Pedro Martinez (to go there)

b. [CAN if you want to go to Harlem][you kiss PM (to go there)]

\section{Kratzer's Theory of Modals and Conditionals}

\subsection{Basic Ingredients of Modal Sentences}

To see the problem posed by Anankastic sentences and understand recent attempts to address it, it is necessary to introduce some background. All the recent work on anankastics start with Kratzer's $(1981,1991)$ theory of modals and conditionals in terms of restricted quantification over possible worlds.

Under Kratzer's theory, modal sentences are interpreted with respect to two contextual parameters, each one a set of propositions (typically implicit) in the conversational background. The first set of propositions is a modal base, which formally is given by a function $f$ that assigns to the world of evaluation $w$ the set $f(w)$, propositions that express relevant facts about $w$ and jointly determine the worlds that the modal operator quantifies over. These could be propositions that are known to hold in the evaluation world, for instance, giving an epistemic modal base, or propositions that express relevant facts about the evaluation world, giving what Kratzer calls a circumstantial modal base. (The sentences considered in this paper chiefly involve modals restricted by circumstantial bases.)

The second contextual parameter is an ordering source-a set of propositions that serves to order the worlds described by the modal base according to how closely they conform to a set of ideals in the conversational background. The ordering source is modeled as the set of propositions $g(w)$, which could express what the laws of $w$ demand (a deontic ordering source), or what our desires, aims, or goals are in $w$ (a bouletic ordering). These propositions partition the worlds in the modal base, determining a strict partial order on them (14-version from von Fintel and Iatridou 2005). And based on that ordering, it is 
possible to select a subset of modal base worlds that are the best possible ones according to the ideals expressed in the ordering source (15).

(14) For any set of propositions $\mathrm{P}$, we define a strict partial order $<_{p}$ : $\forall \mathrm{w}^{\prime}, \mathrm{w}^{\prime \prime}:\left[\mathrm{w}^{\prime}<_{p} \mathrm{w}^{\prime \prime}\right.$ iff $\forall \mathrm{p} \in \mathrm{P}\left[\mathrm{w}^{\prime \prime} \in \mathrm{p} \rightarrow \mathrm{w}^{\prime} \in \mathrm{p}\right]$ and $\left.\exists \mathrm{p} \in \mathrm{P}\left[\mathrm{w}^{\prime} \in \mathrm{p}^{\wedge} \mathrm{w}^{\prime \prime} \notin \mathrm{p}\right]\right]$

For a given strict partial order $<_{p}$ on worlds, we define the selection function $\operatorname{MAX}_{p}$ that selects the set of $<_{p}$-best worlds from any set $\chi$ of worlds: $\forall \chi \subseteq \mathrm{W}: \operatorname{MAX}_{p}(\chi)=\left\{\mathrm{w} \in \chi: \neg \exists \mathrm{w}^{\prime} \in \chi: w^{\prime}<{ }_{\mathrm{p}} w^{\prime}\right\}$

Thus to derive truth conditions for sentences like (16), modal operators like must, can, and the like, take two sets of propositions as arguments before applying to the VP: a modal base $f(w)$ and an ordering source $g(w)$, as in (17).

(16) I must move my car.

(17) $\|$ [must $f(w) \quad g(w)]\left[\mathrm{vP}\right.$ I move my car] $\|^{a . w}=\forall w^{\prime} \in \operatorname{MAX}_{g(w)}(\cap f(w)):$ I move my car in $w^{\prime}$.

"All of the worlds in the modal base that are as good as possible according to the ordering source are such that I move my car."

a. The circumstantial modal base $f(w)$ is the set of propositions that express relevant facts about $w$, such as:

i. My car is parked in front of my apartment.

ii. It is the early afternoon.

b. The deontic ordering source $g(w)$ is the set of propositions that express what the laws of $w$ demand, including:

i. No car is parked in front of my apartment after 1 p.m.

ii. People who park cars in front of my apartment after 1:00 pay a fine.

\subsection{Conditionals: If-Clauses Restrict the Modal Base}

Adopting Lewis's (1975) idea that if-clauses can restrict adverbial quantifiers, Kratzer proposed that if-clauses in conditional sentences serve as an additional restriction on the modal base of a (possibly covert) modal operator.

(18) If it's 2 o'clock, I have to pay a fine.

(19) Conditionals

a. 'If $p$, then must $q$ ' is true in $w$ iff $\forall w^{\prime} \in \operatorname{MAX}_{g(w)}\left(\cap f^{+}(w)\right): q\left(w^{\prime}\right)=1$, where $f+(w)=f(w) \cup p$.

b. 'If $p$, then can $q$ ' is true in $w$ iff $\exists w^{\prime} \in \operatorname{MAX}_{g(w)}\left(\cap f^{+}(w)\right): q\left(w^{\prime}\right)=1$, where $f+(w)=f(w) \cup p$. 
Now, in addition to the modal base propositions (17a), which restrict the modal in terms of certain facts that are true in the evaluation world, the if-clause in (18) expresses a hypothetical fact about the worlds that are quantified over (but is not necessarily true in the evaluation world), namely that it's two o'clock.

Among these further restricted worlds, there are no worlds that are 'ideal' according to the ordering source $(17 \mathrm{~b})$ - since $(17 \mathrm{~b}(i))$ is false in these worlds. But there remains a partition between worlds that are "as close as possible" to the ideal - those in which I pay a fine-and worlds that are farther from the ideal (in which neither $(17 \mathrm{~b}(i))$ nor $(17 \mathrm{~b}(i i))$ holds).

(20) "All of the best possible worlds (according to (17b)) in which the modal base propositions (17a) are true and in which it's two o'clock are such that I pay a fine."

\section{Anankastic Conditional Sentences: A Survey of Approaches}

\subsection{Why the 'Standard Kratzerian Approach' Fails: The 'Mayor Problem'}

Consider the sentence (21), and suppose that all the propositions in (22a) and (22b) are true.

(21) You must go to the pub regularly.

(22) a. The world is such that you will become mayor only if you go to the pub regularly.

b. i. You want to become mayor.

ii. You want not to go to the pub regularly.

Kratzer (1981) described this as "the horrible story of someone who wants something but rejects the necessary means leading to the fulfillment of her desires", and observed that her doubly relative theory of modals correctly predicts (21) to be interpreted as a false sentence under the circumstances.

But Kratzer's theory makes a wrong prediction about the meanings of Anankastic sentences: (23) is predicted to be false as well, wrongly.

(23) If you want to become mayor, you have to go to the pub regularly.

Kratzer's theory adds the if-clause-the proposition that you want to become mayor - to the factual modal base (2la). If the ordering source is picking out the goals that you have in the actual world, it includes both of the desires expressed in (21b). But since there is no way for any of the modal base worlds to satisfy both propositions in the ordering source simultaneously, worlds in which one or the other goal is met are tied for first place. That is, (24) is wrong as a description of the meaning of (23). 
(24) In all of the best possible worlds (according to the two propositions in (21b)) among those jointly described by (21a) and the proposition that you want to become mayor, you go to the pub regularly.

\subsection{Sab $\phi$ 's Insight: If-Clauses Change the Ordering Source}

Sæbø (2001) was the first to address Kratzer's Anankastic problem. His suggestion was that material from the if-clause can be added to the ordering source, rather than adding the whole if-clause to the modal base. Specifically, he proposed that the complement of want can be treated as a hypothetical ideal, rather than the whole if-clause being treated as a hypothetical fact.

\subsection{Sab $\varnothing$ 's Problem, and a Non-Compositional Fix}

But Sæbø's suggestion doesn't solve Kratzer's problem, as was pointed out by von Fintel \& Iatridou (2004) and Penka et al. (2004). Merely adding a proposition to the ordering source won't handle incompatible goals: we'd still end up with mayor-worlds and pub-worlds tied for first place.

Penka et al. (2004) offered an alternative modeled in part on Sæbø's insight: new material is added to the modal base (à la Kratzer)-but just the complement of want, internal to the if-clause (à la Sæbø).

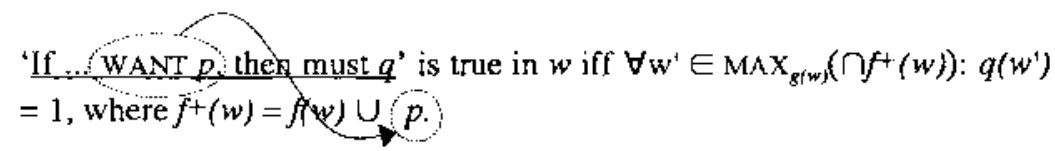

This proposal solves the incompatible goal problem by treating the goal expressed in the if-clause as a hypothetical fact-only worlds in which you become mayor are considered, in effect removing the other goal (not going to the pub) from the ordering source.

Penka et al.'s explanation succeeds (in this instance), but is noncompositional (just like Sæbø's approach): the top layer within the if-clause (the want predicate) has to be ignored.

\subsection{If You Want to Ignore Want: The Central Role of the To-Clause}

Von Fintel \& Iatridou (2004; henceforth vF\&I) propose a way to handle the noncompositionality problem while still achieving the same net result as Penka et al. (namely to treat the if-clause goal as a hypothetical fact). Specifically, vF\&I capitalize on Sæbø's observation that Anankastics can be paraphrased using infinitival rationale clauses (26a), and propose that teleological modals select the 
rationale clause as an argument $(26 b, c) .{ }^{2}$ This infinitival to-clause expresses what vF\&I call the designated goal-a goal that effectively overrides competing goals in the ordering source, in virtue of restricting the modal base worlds to just those where the goal is achieved.

(26) a. To become mayor, you have to $\left(/\right.$ should $\left.^{3}\right)$ go to the pub regularly.

b. [SHOULD $f(w) g(w)$ to become mayor][you go to the pub regularly]

c. (26b) is true in $w$ iff all the $g(w)$-best worlds in $f(w)$ where you become mayor are worlds where you go to the pub regularly.

For anankastics with if-clauses, vF\&I suggest that the infinitival is still present, but elliptical:

(27) If you want to become mayor, you should go to the pub (to become mayor (to do that)

'If wantp. ITop, then should $q$ ' is true in $w$ iff $\forall w^{\prime} \in \operatorname{MAX}_{g(w)}(\cap f(w) \cup p)$ : $q\left(w^{\prime}\right)=1$.

The if-clause can now restrict the modal base in the standard way; its contribution to the truth conditions will be minimal since the work was already done by the toclause. ${ }^{4}$ And, vF\&I argue, the to-clause does the job compositionally. ${ }^{5}$

\subsection{The Ruud van Nistelrooy Problem: Multiple Compatible Goals}

Huitink (2005a) points out a problem that the proposals on the table so far cannot handle. She observes that all the proposals are designed to deal with conflicting goals that are held in the evaluation world (like in Kratzer's mayor scenario). But they fail whenever the ordering source includes multiple goals that do not conflict. She considers Sæbø’s paradigmatic sentence:

(29) If you want to go to Harlem, you have to take the A Train.

Suppose that you have two goals: to go to Harlem, and to kiss the Dutch soccer star Ruud van Nistelrooy. The world is such that the modal base assigns to it the propositions in (30); the ordering source will consist of (31).

(30) Propositions included in the modal base $f(w)$ :

a. You're at Penn Station, deciding whether to get on the A train.

b. Ruud van Nistelrooy is on the northbound A train.

c. If you get on the northbound A train, you can go to Harlem.

(31) Propositions in the ordering source $g(w)$ describing what you want in $w$ :

a. You go to Harlem.

b. You kiss Ruud van Nistelrooy. 
Huitink points out that the analyses of Penka et al. and vF\&I (which result in the proposition in the scope of want in the if-clause being added to the modal base) predict (29) to be true, correctly - but they also predict (32) to be true!

(32) \#If you want to go to Harlem, you have to (should) kiss Ruud van Nistelrooy.

To see why, consider the structure of (32) under vF\&I's designated goal analysis ${ }^{6}$ :

(33) If you want to go to Harlem, you should kiss RvN (to go to Harlem)

(34) a. Truth conditions (without the if-clause):

True iff all the $g(w)$-best worlds in $f(w)$ where you go to Harlem are such that you kiss Ruud van Nistelrooy.

b. Truth conditions (with the if-clause, essentially the same):

True iff all the $g(w)$-best worlds in $f(w)$ where you both want to go to Harlem and you go to Harlem are such that you kiss RvN.

In the actual world $w$, both the $g(w)$ goals stated in (31) are attainable as long as you get on the A train. If so, unlike Kratzer's mayor scenario, the set of $g(w)$-best worlds are such that both propositions hold. Hence the truth conditions stated in (34) are met.

\subsubsection{Huitink's Solution: 'Salient Goals'}

Huitink's solution is to abandon Kratzer's assumption that the ordering source necessarily picks out all of the goals held in the evaluation world. Instead, she proposes that the if-clause can serve to introduce a salient goal into the contextin effect introducing a bouletic conversational background consisting solely of the if-clause goal.

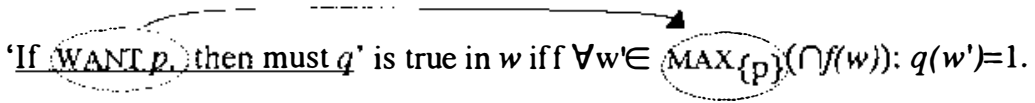

Under Huitink's proposal, the ordering source contains just one goal-the one expressed in the if-clause. As a result the Ruud van Nistelrooy sentence (32) is no longer predicted to be true.

(36) Prediction about (32): FALSE (a correct prediction)

True iff, in all the best (i.e. go-to-Harlem) worlds in $f(w)$, you kiss Ruud.

(37) Prediction about (29): TRUE (also a correct prediction)

True iff in all the best (=go-to-Harlem) worlds in $f(w)$, you take the A train 


\subsection{Another Contender: vF\&I's Nested Modals Analysis}

Another theory that I think remains on the table was proposed by vF\&I in the same 2004 paper in which they proposed their 'designated goal' analysis. Although they did not end up adopting this theory in the final analysis, I think it is worth mentioning because it not only overcomes Kratzer's mayor problem, it also successfully handles Huitink's Ruud van Nistelrooy problem. In short, vF\&I suggested that anankastic sentences have an extra (covert) modal operator, and that it is this modal whose (epistemic) modal base the if-clause restricts. Thus, the structure of sentences like (23) and (32) would be:

(38) [<MUST $>$ if you want to become mayor][HAVE-TO you go to the pub...]

(39) [ $\quad$ MUST $>$ if you want to go to Harlem][HAVE-TO you kiss Ruud...]

If this is the structure of an anankastic, competing goals held in the actual world (such as 'not going to the pub') would be irrelevant for the interpretation of (38). The ordering source for the embedded modal is supplied not by a function of the utterance world, but by the goal stated in the if-clause that restricts the higher modal. For exactly-the same reason, non-competing goals held in the actual world would be irrelevant for the interpretation of (39).

\section{4. 'Existential' Anankastics?}

\section{Kissing Pedro Martinez: The Problem Posed by Sufficiency Conditionals}

Consider a scenario very similar to Huitink's Ruud van Nistelrooy scenario, this one involving the former Red Sox pitching ace Pedro Martinez. Suppose in particular that Pedro Martinez is on the northbound A train and that you'd like to kiss him. In addition, you wouldn't mind going to Harlem.

Nevertheless, (40a) and (40b) are false.

(40) a. \# If you want to get to Harlem, you can kiss Pedro Martinez.

b. \# In order to get to Harlem, you can kiss Pedro Martinez.

All of the proposals currently on the table fail to predict this. Huitink would have the ordering source consist solely of the salient goal of getting to Harlem; the designated goal analysis of vF\&I would promote that goal by adding the proposition that you get to Harlem to the modal base; their nested modals analysis would yield an ordering source (for the lower modal) consisting of just the proposition that you get to Harlem. In all of these cases, it's easy to satisfy the truth conditions of (40). 
(41) What Huitink needs to say:

'If WANT $p$. CAN $q$ ' is true in $w$ iff $\exists w^{\prime} \in \operatorname{MAX}_{\{p\}}(\cap f(w)): q\left(w^{\prime}\right)=1$.

$\rightarrow(40)$ is true in $w$ iff at least one of the best $(=$ Harlem) worlds in $f(w)$ is such that you kiss Pedro Martinez.

(42) What vF\&I need to say (similarly, Penka et al.):

'IIf want $p$ ) To $p$. CAN $q$ ' is true in $w$ iff $\exists w^{\prime} \in \operatorname{MAX}_{g(w)}(\cap f(w) \cup p): q\left(w^{\prime}\right)=1$.

$\rightarrow(40)$ is true in $w$ iff at least one of the $g(w)$-best get-to-Harlem worlds in $f(w)$ is such that you kiss Pedro Martinez.

(43) What the $\mathbf{v F} \& I$ nested modals analysis would need to say:

' $\angle M U S T \geq$ if want p. CAN $q$ ' is true in $w$ iff $\forall w ' \in \cap f(w) \cup p$ :

$\left[\exists w^{\prime \prime} \in \operatorname{MAX}_{g\left(w^{\prime}\right)}\left(\cap f\left(w^{\prime}\right)\right): q\left(w^{\prime \prime}\right)=1\right]$.

(40) is true in $w$ iff for all of the epistemically accessible worlds $w^{\prime}$ such that your goal is to get to Harlem, at least one of the $g\left(w^{\prime}\right)$-best (=Harlem) worlds is such that you kiss Pedro Martinez.

Under those conditions, (40) is surely true; it hard to imagine a reason why there wouldn't be an accessible world in which your goal of getting to Harlem is reached and you also kiss Pedro Martinez, given that he's on the very train that takes you where you want to go.

Note that $(44 a, b)$ are felicitous under the same circumstances-if it the case (and it is) that both the $\mathrm{A}$ and the $\mathrm{C}$ trains will take you to Harlem.

a. If you want to get to Harlem, you can take the A train.

b. You can take the A train in order to get to Harlem.

These sentences are understood to mean taking the A train is one way to achieve the goal of getting to Harlem - that that action constitutes a sufficient condition (together with facts in the circumstantial modal base) for achieving the goal.

This observation is important, since it shows that one cannot simply stipulate that the anankastic reading is limited to modal operators with universal force. Existentials can in principle get 'anankastic-like' (eparkastic) readings.

What is needed is a theory that predicts (44) to be true while also predicting the Pedro Martinez sentence (40) to be false.

\section{A Suggestion}

I would like to suggest an approach to the problem of sufficiency conditionals that appropriates a core part of $\mathrm{vF} \& \mathrm{I}$ 's 'designated goal' theory, but rejects one of its important details. Specifically, we might accept $\mathrm{vF} \& \mathrm{I}$ 's insight that infinitival toclauses are always what's responsible for inducing the relevant reading-while dispensing with their assumption that it restricts a modal operator. After all, 
infinitival to-clauses can appear with ordinary VPs that aren't in the scope of a modal. And when they do, they still typically express something about the goals of the VP's agent.

\subsection{Rationale Clauses in Non-Modal Environments}

Infinitival to-clauses can appear in the environment of non-modal main clauses, where they nevertheless have a teleological interpretation:

(45) Varitek took the A train to get to Harlem.

(46) Menino went to the pub regularly to become mayor.

(47) Satsuki's father drank green tea in order to remain healthy.

(48) Rogers and Astaire practiced every day in order to dance professionally.

Rationale clauses themselves are interpreted as modal expressions, ordinarily describing the desires, aims and intentions of agents. For instance, (45) implies that Varitek's goal in taking the A train was to get to Harlem; he must have believed it to be either a necessary or sufficient condition for getting there, given other relevant facts about the world. And non-agentive VPs typically sound odd with rationale clauses - they are coerced into agentive readings:

(49) \# Those leaves turned colors in order to be attractive.

(50) \# Brad was bleeding in order to prove a point.

Thus, ordinary agentive VPs are understood teleologically: they describe goaldirected actions. Rationale clauses serve to describe the goals that direct those actions.

I think that what we should learn from such sentences is that a crucial component of anankastic readings-specifically, the expression of an agent's goal in undertaking an action-is supplied internal to the $V P$, independent of an embedding modal verb.

Here is a way of implementing the idea compositionally. This method assumes that both VPs and rationale clauses denote predicates of events, and compose by Predicate Modification. Altemative assumptions could undoubtedly be made (e.g. that the verb takes the rationale clause as an argument, or that the rationale clause takes the VP as its argument). I don't think anything I have to say about these VPs hinges on any of these choices.

(51) Denotations for VPs and rationale clauses

a. $\|_{\text {vP }}$ Varitek take the $\mathrm{A}$ train $\|^{\text {a.w }}=$ $\lambda$ e.[event $(e) \&$ taking-the-A-train $(e)(w) \& \operatorname{Agent}(e)($ Varitek)] 
b. $\|_{\text {adjunct }}$ (in order) to go to Harlem $\|^{\text {a.w }}=$

$\lambda e . \forall w^{\prime}\left[w^{\prime}\right.$ is compatible with the goals relevant to $e$ : PRO goes to Harlem at $\left.w^{\prime}\right]$

According to (51a), the VP in (45) just denotes the predicate that is true of any Atrain-taking event in $w$ whose agent is Varitek.

As for the adjunct's denotation (51b), there are two things to note. First, it is a more or less standard (modulo the difference noted in the next paragraph) description of a desire modeled after Hintikka's semantics for propositional attitudes (Hintikka 1969, von Fintel \& Heim 2005). The facts above (45-50), I think, lead us to the conclusion that $t o$-clauses, at least in this environment, are modal statements and not bare propositions. Assuming that all infinitival toadjuncts receive a unified treatment, this observation is incompatible with the claim (made, for example, by $\mathrm{vF} \& \mathrm{I}$ ) that an infinitival clause $[t o p]$ can serve to add the proposition that $\boldsymbol{p}$ (compositionally) to the modal base of a modal operator. Rather, adding [to $p$ ] to a modal base would be equivalent to adding the proposition [... want that $p]^{?}$.

Second, the goal described by a rationale clause is stated relative to the lambda-abstracted event, on a par with the way modal accessibility is defined in relation to an evaluation world. This requires that we take event and world variables to be of the same essential type. Goals can be relevant to a possible world $w$, for instance the goals expressed by propositions that are assigned to $w$ by the ordering source of a modal verb. The goals described in (51b) as being "relevant to $e$ ", where $e$ is an agentive event, are simply the goals held by the agent of $e$ that are relevant to carrying out the action that describes $e$. I don't think this is adding anything significant beyond what must be implicitly assumed about the notion agentivity.

Closure over the conjunction of (51a) and (51b) yields true (given an assignment $a$ and world $w$ ) iff Varitek is the agent of an A-train-taking event $e$ in $w$ whose goal is that he goes to Harlem. ${ }^{8}$

\subsection{Teleological VPs and Necessity Conditionals}

If ordinary agentive VPs have teleological meanings, then the teleological component of an Anankastic Conditional's meaning doesn't need to be specified by an argument of the modal. ${ }^{9}$ In (52a), the rationale clause modifies the VP, and is within the scope of the modal:

(52) a. HAVE-TO $f(w) g(w)$ [you take the A train in order to get to Harlem]

b. True iff, in all of the $g(w)$-best worlds in $f(w)$, you are the agent of an A-train-taking event $e$ whose goal is that you go to Harlem. 
When $f(w)$ is a circumstantial modal base and $g(w)$ is a bouletic ordering source that picks out your goals in $w$, the interpretation of (52a) will be anankastic. The goal expressed by the rationale-clause-because it is in the scope of the modalis a goal held in worlds quantified over by the modal. But since the modal base is circumstantial, relevant facts about $w$ will be true of the quantified-over worlds as well, including (presumably; see note 12) the fact that your goal is to go to Harlem.

Let's assume, following vF\&I, that in conditionals with an if-clause and no overt rationale clause, the if-clause restricts the modal base and the rationale clause is elliptical:

a. If you want to go to Harlem, HAVE-TO $f(w) g(w)$ [you take the A train 〈in order to go there)]

b. True iff, in all of the $g(w)$-best worlds in $f(w)$ where you want to go to Harlem, you are the agent of an A-train-taking event $e$ whose goal is that you go there.

Truth conditions like these still make wrong predictions in scenarios with additional goals (like Kratzer's mayor scenario, or Huitink's Ruud scenario)_if the ordering source $g(w)$ necessarily picks out all of your goals in $w$, the world of evaluation. For instance, if one of your goals in $w$ is 'that you don't take the $A$ train', then it won't be the case that all of the $g(w)$-best worlds are A-train worlds. So the sentence corresponding to (53) would be predicted, wrongly, to be false in that scenario. ${ }^{10}$

To make the right predictions then, the VP-level analysis for the to-clause in anankastic sentences still requires a supplementary assumption to block interfering goals from the ordering source. As far as I can see, there are two viable proposals to choose from: Huitink's salient goals, and vF\&I's nested modals. ${ }^{11}$ It would be quite straightforward to supplement the VP-level analysis $(52,53)$ with Huitink's proposal. We would only need to assume that it is (ultimately) the VPadjoined rationale clause-not the if-clause-that makes the goal salient. That would reduce $g(w)$ to the single proposition that you go to Harlem. The nested modals idea would work equally well. Then, for example, (53a) would be modified to (54a), yielding the truth conditions stated in (54b):

a. [<MUST $f(w)$ if you want to go to Harlem][HAVE-TO $f\left(w^{\prime}\right) g\left(w^{\prime}\right)$ [you take the A train in $w^{\prime}$ (in order to go there)]]

b. True iff, in all of the epistemically accessible worlds $w^{\prime}$ in which what you want is to go to Harlem: all the $w^{\prime}$-best worlds that are circumstantially accessible from $w^{\prime}$ are such that you are the agent of an A-train-taking event $e$ whose goal is that you go there.

That seems to get the truth conditions of Anankastics right. ${ }^{12}$ 
To sum up what I think I've shown so far in this section, to-clauses can appear as VP-adjuncts in non-modal environments. The right semantics for toclauses treats them as modal propositions describing goals; consequently, the teleological component of anankastics comes from the scope of the modal rather than its restriction. I concluded with the observation that the goal nevertheless needs to appear in the modal restriction. This observation makes my VP-level suggestion seem superfluous. In the next subsection I'll argue that it's necessary after all, since it offers a way around the problem of kissing Pedro Martinez.

\subsection{The Teleological Nature of VPs Solves the 'Sufficiency Conditional' Problem}

What about the Pedro Martinez problem? The claim that modal verbs take teleologically interpreted VPs allows a solution for it. Recall that the problem was to predict (44) to be true and (40) to be false:

(44) If you want to get to Harlem, you can take the A train.

(40) \#If you want to get to Harlem, you can kiss Pedro Martinez.

Suppose, as argued in the previous subsection, that the goal expressed in the rationale-clause projects up to the ordering source for the modal. Then, if the possibility modal contains an elliptical to-clause in its scope, interpreted as a description of the goal of the agentive VP, exactly these predictions are made:

(55) Truth conditions for (44):

a. If you want to go to Harlem, CAN $f(w) g(w)$ [you take the A train (in order to go there)]

b. True iff, in all of the $g(w)$-best worlds in $f(w)$ where you want to go to Harlem, you are the agent of an A-train-taking event $e$ whose goal is that you go there.

(TRUE)

(56) Truth conditions for (40):

a. If you want to go to Harlem, CAN $f(w) g(w)$ [you kiss Pedro Martinez 〈in order to go there)]

b. True iff, in at least one of the $g(w)$-best worlds in $f(w)$ where you want to go to Harlem, you are the agent of a Pedro-Martinez-kissing event $e$ whose goal is that you go there.

(FALSE)

It is plain that the deviance of (40) results from the deviance of (57), which remains deviant when embedded under can:

(57) \#I kissed Pedro Martinez in order to go to Harlem. 


\section{Some Problems, and Tentative Remarks About How to Approach Them}

\subsection{The Pedro Martinez Problem Might be Pragmatic}

Janneke Huitink (2005b, and p.c.) points out that the Pedro Martinez problem may be a more general problem for any existential conditional. The problem with Pedro Martinez sentences like (40a), Huitink speculates, is that "the antecedent and the consequent are unrelated, and therefore it is strange that there should be a conditional relation between them." She equates my example with others like:

(58) If the Democrats win, the butler may have committed the murder.

and states that "the problem of unrelated antecedents and consequents is not a semantic problem but a pragmatic one", which should be solved by means of a felicity condition on if-clauses: namely that "conditionals have to be informative".

I fully agree with Huitink's suggestion that there must be a felicity condition on the use of $i$-clauses, which affects existential conditionals. However, I think the problem can be further pinpointed: it's not just that "conditionals have to be informative", rather, that "if-clauses must not be superfluous." Huitink demonstrates the superfluousness of the if-clause in (58) by noting that the sentence remains true if the main clause is negated.

Note, however, that in Pedro Martinez sentences, it is not the if-clause that is superfluous-it is the main clause. In an 'existential anankastic' (or eparkastic) the if-clause expresses the desired goal. What makes (40) false, intuitively, is that the action describe by the main clause (kissing Pedro) is irrelevant for achieving the goal. A felicity condition demanding non-superfluous if-clauses would suffice for other non-anankastic existential conditionals. Pedro sentences seem to fall under a different generalization. Moreover, Huitink's felicity condition doesn't explain why the rationale-clause paraphrase (40b) is likewise false, since that is not a conditional. There too, the main clause seems responsible.

b. \# In order to go to Harlem, you can kiss Pedro Martinez.

\subsection{Non-Agentive VPs}

Kai von Fintel (p.c.) has pointed out a different problem, one which leads to the conclusion that infinitival to-clauses, at least sometimes, are not parsed as VPmodifiers in the scope of modals. Consider the two sentences of (59). These both receive anankastic interpretations: they express a necessary condition (knowing French) for achieving an outcome (working in the public schools).

(59) a. You have to know French if you want to work in the public schools.

b. You have to know French in order to work in the public schools. 
Unlike the sentences considered throughout this paper, however, the VP of the main clause is not agentive: it describes the (non-volitional) state of knowing French. Consequently, it cannot be modified by a purposive to-clause:

(60) \# Jean knows French in order to get a job in the public schools.

If anankastic readings were always derived in the manner suggested in section 5 , then the VPs in (59) would have to be in all relevant respects identical to (60)predicting both $(59 a-b)$ to be deviant as well, wrongly. That is, by the logic of section 5 , the deviance of (60) should lead to the deviance of (59). The to-clause in (59b) seems not to have an available parse as a VP-modifier.

I argued at the end of section 5.2, however, that my VP-level analysis is compatible with, but not necessary for anankastic readings with universal modal operators. The VP-level analysis is necessary when the modal is existential (as I argued in sections 4 and 5.3). And interestingly, when the universal modals in non-agentive environments like (59) are replaced by existentials (60), the relevant readings disappear. This looks very much like support for the claim that the VPlevel analysis is crucial for existential versions of anankastic sentences.

(61) a. \#You can know French if you want to work in the public schools.

b. \#You can know French in order to work in the public schools.

What about the interpretations of $(59 a, b)$ ? With regard to the anankastic conditional (59a), the two options I suggested at the end of section 5.2 (or the third one that I suggested in note 12) allow for a straightforward interpretation without a VP-level to-clause. As for (59b), the only tenable attachment site for the to-clause is evidently at the level of the modal verb, raising the obvious question whether the modal semantics I gave for to-clauses in section 5.1 will work (or whether Bech 1957 was right in claiming that anankastic to-clauses differ from rationale clauses). As far as I can see, my modal version of to-clauses (51b) works well for (59b), if the modal proposition is added to the modal base (indirectly providing a goal for the ordering source). Roughly, the sentence would be true in $w$ iff, in all of the $g(w)$-best worlds among those in which the relevant goal is that you work in the public schools, you know French.

\section{Endnotes}

* I stumbled onto this topic while undertaking a project on the syntax and semantics of rationale clauses. I owe a big debt of gratitude to Kai von Fintel and Sabine Iatridou, Janneke Huitink, and Arnim von Stechow and his colleagues, who by sharing their work in progress (which I got to via Kai's weblog) made it possible for an onlooker like me to benefit from and take part in the public 
discussion they were having. In addition, Kai von Fintel, Janneke Huitink, Alan Bale, Yosef Grodzinsky, and Martin Hackl provided extremely helpful comments and criticisms at various stages. I also wish to thank the other participants at the SALT conference. This work was supported by the Fonds Québécois de la Recherche sur la Société et la Culture, award \# 99440.

${ }^{1}$ Actually, this is not quite right. It is more accurate to say that (10a) is equivalent to the statement "If $\mathrm{q}$ and other relevant facts about the world hold, then $\mathrm{p}$ ". See section 2 for a more thorough description and justification of this qualification. I thank Kai von Fintel (p.c.) for calling this to my attention.

${ }^{2} \mathrm{As}$ vF\&I hint in their paper, it would work just as well to treat the to-clause as an adjunct that restricts the modal base rather than an extra argument of the modal.

${ }^{3} \mathrm{vF} \& \mathrm{I}$ argue for a distinction between have to/must, on the one hand, and ought to/should on the other. For have to/must, they give an interesting argument that the ordering source effectively plays no role-i.e. the proposition in the scope of want in the if-clause is required to hold in all the worlds quantified over by the modal, regardless of any other desires, etc. that are held in the evaluation world.

${ }^{4}$ Von Stechow et al. (2005) independently propose this idea but take it in a different direction: they propose the to-clause restricts the modal base of something like a counterfactual conditional. For discussion see Huitink (2005b).

${ }^{5}$ But see section 5.1 for an argument that this wouldn't actually be compositional.

${ }^{6}$ Given the distinction mentioned in note 3, Huitink's observation applies just to anankastics with ought/should under their theory.

${ }^{7}$ Perhaps it is not obvious that we want a unified treatment for to-adjuncts, however. See Bech (1957) for an argument that to-clauses come in two flavors. I will proceed under the assumption that a unified treatment is desirable, if possible. In section 6.2 I give a sketch of an argument that it is.

${ }^{8} \mathrm{I}$ assume the open event argument is existentially closed and that modal verbs compose with an intensional abstraction over the VP's denotation.

${ }^{9} \mathrm{Or}$, more generally, by an additional restriction on the modal base. See note 2 .

${ }^{10}$ I am grateful to Kai von Fintel for noticing this and pointing it out to me.

${ }^{11}$ The 'designated goal' fix advocated by vF\&I - adding the bare proposition that you go to Harlem to the modal base-isn't a viable option if the elliptical tophrase is actually a modal statement, as I argued in the previous subsection.

${ }^{12}$ I believe there might actually be a third, more parsimonious option for eliminating the problem of interfering goals, which may not have been brought up so far. Let's accept that every proposition $p$ in an ordering source $g(w)$ has a corresponding proposition in a circumstantial modal base ordered by $g(w)$ : e:g. that "the laws of $w$ demand that $p$ ", "One of Sue's goals in $w$ is that $p$ ", etc. (Such descriptions of the propositions in the ordering source surely count as "relevant facts about $w$.') Let's assume further that an if-clause like "if you want $p$ " can add to the modal base the hypothetical proposition that what you want in $w$ is that $p$ '. Since the propositions in a circumstantial modal base must be consistent, adding such a proposition entails that the modal base doesn't contain descriptions of any 
other desires of yours in $w$. That in turn entails that the ordering source (if it picks out what you desire in $w$ ) contains only $p$. If this reasoning is correct, then there is no mayor problem (or Ruud problem): anankastic conditionals simply add the ifclause to the modal base, and the option of limiting the ordering source to the corresponding singleton proposition follows.

I think this option is attractive. I'm not sure if it's really distinct from Huitink's salient goal theory, although I stated it somewhat differently.

\section{References}

Bech, Gunnar: 1957, Studien über das Deutsche Verbum Infinitum, Niemeyer, Tübingen.

von Fintel, Kai and Irene Heim: 2005, Intensional Semantics Lecture Notes, draft at: [http://semantics-online.org/advsem/IntensionalSemantics.pdf].

von Fintel, Kai and Sabine Iatridou: 2004, 'What to Do If You Want to Go to Harlem: Notes on Anankastic Conditionals and Related Matters', draft at: [http://web.mit.edu/fintel/www/harlem.pdf].

Hintikka, Jaakko: 1969, 'Semantics for Propositional Attitudes', in J.W. Davis, et al. (eds.) Philosophical Logic, Reidel, Dordrecht, 21-45.

Huitink, Janneke: 2005a, 'Anankastic Conditionals and Salient Goals', in E. Maier, C. Bary and J. Huitink (eds.), Proceedings of Sinn und Bedeutung 9: [http://www.phil.kun.nl/tfl/janneke/Huitink-SUB9.pdf].

Huitink, Janneke: 2005b, 'Analyzing Anankastic Conditionals and Sufficiency Modals', in Proceedings of ConSOLE XIII, Draft at: [http://www.phil.kun.nl/tfl/janneke/console13-revised-Huitink.pdf].

Kratzer, Angelika: 1981, 'The Notional Category of Modality', in H. Eickmeyer et al. (eds.) Words, Worlds and Contexts, Walter de Gruyter, Berlin, 38-74.

Kratzer, Angelika: 1991, 'Modality', in A. von Stechow and D. Wunderlich (eds.) Semantik: ein Internationales Handbuch der Zeitge-nossischen Forschung, Walter de Gruyter, Berlin, 639-650.

Lewis, David: 1975, 'Adverbs of Quantification', in E. Keenan (ed.) Formal Semantics of Natural Language, Cambridge University Press, UK, 3-15.

Penka, Doris, Sveta Krasikowa and Arnim von Stechow: 2004, 'The Meaning of German um zu: Necessary Condition and Enough/Too', handout of a presentation at Modal Verbs and Modality, University of Tübingen.

Sæbø, Kjell Johan: 2001. 'Necessary Conditions in a Natural Language', in C. Féry and W. Sternef eld (eds.) Audiatur Vox Sapientiae: a Festschrift für A von Stechow, Akademie Verlag, Berlin, 427-449.

von Stechow, Arnim, Sveta Krasikowa and Doris Penka: 2005, 'Anankastic Conditionals', ms, University of Tübingen: [http://vivaldi.sfs.nphil.unituebingen.de/ arnim 10/Auf saetze/NEC.COND.7.pdf].

von Wright, G. H.: 1963. Norm and Action, Routledge, London. 